\title{
Insoluble Vegetable Fiber as a Potential Functional Ingredient: Invitro Studies on Hypoglycemic and Hypocholesterolemic Effect
}

\author{
Dhiraj D. Gohil, S. S. Lele* \\ Food Engineering and Technology Department, Institute of Chemical Technology, Matunga, Mumbai, India \\ *Corresponding author: dr.smita.lele@gmail.com
}

Received October 16, 2013; Revised February 19, 2014; Accepted February 24, 2014

\begin{abstract}
Vegetable and fruit derived fibre plays a crucial role in promoting good health. Soluble and insoluble fiber has different physiological roles in human body. Insoluble fiber is known for having several beneficial effects like anti-constipating, hypoglycemic, hypocholesterolemic. In the present study, insoluble dietary fiber from vegetables viz., Nelumbo nucifera, Murraya koenigii, Abelmoschus esculentus and Brassica oleracea were investigated in vitro for their hypoglycemic and hypocholesterolemic effect. The hypoglycemic effect was studied by measuring glucose adsorption, glucose diffusion and amylase inhibitory activity whereas hypocholesterolemic effect was observed by bile salt (Sodium cholate) adsorption study. Results indicate that $N$. nucifera exerts significanteffect on glucose adsorption $(7.40 \pm 0.14 \mathrm{mmol} / \mathrm{g})$ and amylase inhibitory activity $(13.19 \pm 0.66 \%)$. Similarly glucose diffusion studies showed low diffusion values in case of $N$. nucifera as compared to others up to an hour. Also, $N$. nucifera showed highest sodium cholate binding capacity $(10.11 \pm 0.20 \%)$ compared to other fibres when cellulose was used as a control. Thus, this study suggests that insoluble fibre from N. nucifera can be used for fortification of functional food products aimed at controlling glucose and cholesterol level.
\end{abstract}

Keywords: hypoglycemic, hypocholesterolemic, vegetables insoluble fiber

Cite This Article: Dhiraj D. Gohil, and S. S. Lele, "Insoluble Vegetable Fiber as a Potential Functional Ingredient: Invitro Studies on Hypoglycemic and Hypocholesterolemic Effect." American Journal of Food Science and Technology, vol. 2, no. 2 (2014): 48-52. doi: 10.12691/ajfst-2-2-1.

\section{Introduction}

Dietary fiber is the edible part of plant or an analogous carbohydrate that is resistant to digestion in intestine [1]. Based on water solubility, dietary fiber is grouped into two categories namely soluble dietary fiber which is well fermented by human colonic bacteria and insoluble dietary fiber thatis poorly fermented [2]. High fiber diet reduces the risk of many diseases like cancers, cardio-vascular disease, obesity, gastrointestinal disorders and diabetes $[3,4,5,6]$.

The hypoglycemic and hypocholesterolemic potential of dietary fibers in managing diabetes and cardiovascular disease is very well documented [3,5,7]. In various studies, hypoglycemic effect of dietary fibers has been investigated $[8,9,10,11,12,15]$. The mechanism by which dietary fibre exerts hypoglycemic effect includes inhibiting amylase activity, glucose adsorption and glucose diffusion [10,11]. Apart from hypoglycemic effect, dietary fibre also exerts hypocholesterolemic effect by binding bile salts leading to their increased fecal excretion $[16,17,18]$. This in turn promotes utilization of endogenous cholesterol in bile salt synthesis leading to an overall hypocholesterolemic effect [12,13].
The hypoglycemic and hypocholesterolemic effect of dietary fibres has been investigated in studies wherein the fibre was used in the form of isolated constituents, fiberrich foodstuffs or fiber fractions.However, the role of insoluble fibers from whole vegetable remains unexplored. Furthermore, soluble fibre undergoes fermentation leading to production of short chain fatty acid [19] whereas most of the insoluble dietary fibres are excreted. The insoluble fiber is very well known as an anti-constipation agent through its water holding capacity is very well known. Thus, the present study was undertaken to explore the health promoting effect of insoluble fibre from locally available vegetables viz. Nelumbo nuciferaStem (Lotus stem), Murraya koenigiileaves (Curry leaves), Abelmoschus esculentusvar. PusaSawani (Okra) and Brassica oleracea var. capitata(Green Cabbage) by determining the capabilities of these fibers in lowering serum glucose and cholesterol level.

\section{Materials and methods}

\subsection{Materials}

All vegetables were procured from local Mumbai market. Sodium cholate was purchased from SigmaAldrich (Mumbai, India) and all other chemicals and 
enzymes were obtained from HiMedia laboratories (Mumbai, India). The chemicals were all of analytical grade. Heat stable alpha-amylase, amyloglucosidase were gifted by Genencore(Mumbai, India). Glucose Assay kit (Eco-pak kit, GOD-POD) was purchased from Accurex Biomedical Pvt. Ltd. (Mumbai, India).

\subsection{Extraction of Insoluble Dietary Fibers}

Vegetables procured from the local market were cleaned and dried at $60^{\circ} \mathrm{C}$. The extraction of vegetable insoluble fibers was done by enzymatic extraction using standard Association of Official Analytical Chemists (AOAC 1990)method.The defatted vegetable powder was digested with heat stable alpha-amylase $\left(100^{\circ} \mathrm{C}, 1 \mathrm{~h}\right)$ and then digested with protease $\left(60^{\circ} \mathrm{C}, 1 \mathrm{~h}\right)$, followed by incubation with amyloglucosidase $\left(60^{\circ} \mathrm{C}, 1 \mathrm{~h}\right)$ to remove protein and starch. The enzyme treated mixture was centrifuged (5000 rpm for $20 \mathrm{~min}$ at $25^{\circ} \mathrm{C}$ ). The residue recovered (IDF) was washed thrice with water, 70\% ethanol, absolute ethanol and acetone sequentially. The residue was oven-dried $\left(60^{\circ} \mathrm{C}\right.$, Overnight) and stored for further analysis.

\subsection{Estimation of Glucose Adsorption Capacity}

The glucose-adsorption capacity was determined in accordance with method mentioned in [11]. $1 \mathrm{~g}$ of fibers and cellulose (Alphacel-Nonnutritive fiber, ICN Nutritional Biochemicals, Cleveland, $\mathrm{OH}$ ) was mixed with $100 \mathrm{ml}$ of glucose solution, concentration ranging from 5$50 \mathrm{mmole} / \mathrm{l}$. The mixture was stirred, held in a water bath at $37^{\circ} \mathrm{C}$ for $6 \mathrm{~h}$, followed by centrifugation at $3500 \mathrm{~g}$ for 15 min. At the end of absorption, the glucose content in the supernatant was measured using the Glucose assay kit to estimate the amount of glucose adsorbed on the fibers.

\subsection{Estimation of Glucose Diffusion and Glucose Dialysis Retardation Index (GDRI)}

Glucose dialysis retardation index was determined as given in [8] with slight modifications. A solution was prepared by mixing $0.1 \mathrm{gm}$ of fiber sample in $5 \mathrm{ml}$ of glucose solution (10mmole/l) and was dialyzed against 40 $\mathrm{ml}$ of distilled water at $37^{\circ} \mathrm{C}$ using a dialysis membrane with a molecular weight cut off value of 12,000 D. After incubation of 20,30,60, 120 and $180 \mathrm{~min}$ the glucose content in the dialysate was measured by Glucose Assay kit. A control test was also prepared without addition of fiber.

The GDRI was calculated using following equation (1):

$$
\text { GDRI }=100-\left[\left(\begin{array}{c}
\text { Glucose content in dialysate } \\
\frac{\text { with fiber addition }}{\text { Glucose } \text { content in dialysate }} \\
\text { with no fiber addition }
\end{array}\right) \times 100\right] \text { (1) }
$$

\subsection{Analysis of Alpha-Amylase Activity}

The effect of fiber on glucose production rate and amylase inhibitory activity was determined as per [8] with slight modifications. An incubation mixture containing $0.25 \mathrm{gm}$ of fiber sample and $1 \mathrm{gm}$ of alpha-amylase in 10 $\mathrm{ml}$ of potato starch solution $(4 \mathrm{gm} / 100 \mathrm{ml})$ was incubated at $37^{\circ} \mathrm{C}$. After $60 \mathrm{~min}$, starch digestion was stopped by addition of absolute ethanol $(15 \mathrm{ml})$. Then it was centrifuged at $3500 \mathrm{rpm}$ for $15 \mathrm{~min}$ and the supernatant was analyzed for glucose content to obtain the glucose production rate ( $\mu$ mole per hour) by Glucose Assay kit. A control test was also done without addition of fiber. The amylase inhibitory activity (\%) was defined as the percent decrease in the glucose production rate over the control.

\subsection{Quantification of Sodium Cholate Binding}

The binding experiment was performed using methodology as suggested by [20]with some modifications. Sodium salt of cholic acid, a primary bile acid was used in the study. Two grams of dietary fibers were incubated with 10 mmole/l sodium cholate in $100 \mathrm{~mL}$ of phosphate buffer ( $\mathrm{pH}$ 7.0). The mixture was agitated $120 \mathrm{rpm}$ for $3 \mathrm{~h}$ at $37^{\circ} \mathrm{C}$. At the endof adsorption, $2 \mathrm{~mL}$ of the sample was collected, and absolute ethanol $(8 \mathrm{~mL})$ was added. After centrifugation (4000g for $20 \mathrm{~min}$ ) the concentration of cholate in the supernatant was determined by the colorimetric assay, where $50-\mu \mathrm{l}$ samples were pipetted into 2-ml polypropylene tubes before adding $800 \mu \mathrm{l}$ of concentrated sulfuric acid. Tubes were vortexed and allowed to cool to room temperature, and absorbance was determined at 389 .

\subsection{Statistical Analysis}

All analysis were done in triplicate and are expressed as mean value \pm S.D. The statistical significance was assessed by one way analysis of variance followed by Tukey's test for the determination of level of significance using GraphPad Prism 5.0.

\section{Results and Discussion}

\subsection{Effect on Glucose Adsorption}

A series of different concentrations of glucose (5$50 \mathrm{mmole} / \mathrm{l})$ were used to study glucose adsorption capacity of vegetable insoluble fibers. As seen in Figure 1, adsorption capacities of $N$. nucifera, A. esculentus and $B$. oleracea $(0.03-7.40 \mathrm{mmole} / \mathrm{g})$ were significantly higher $(\mathrm{p}<0.01)$ compared to that of $M$. koenigii and cellulose (0.08-4.72 mmole/g) at a different glucose concentration. At high glucose concentration (50mmole/l), adsorption capacity of $N$. nucifera and A. esculentus was significantly $(\mathrm{p}<0.01)$ higher as compared to others and cellulose. When low glucose concentration used (5mmole/l), the glucose-adsorption capacity of fibers was found to be 0.03-0.69 mmole/g. At 5mmol/l glucose concentration, $N$. nucifera $(0.69 \pm 19 \mathrm{mmole} / \mathrm{g}) \mathrm{has}$ the highest adsorption capacity. Thus, the results indicated that the fibers could effectively bind to glucose even at low concentrations of glucose thereby reducing the amount of accessible glucose in small intestinal.It is observed that the glucose adsorption capacity of fibers is directly related to available glucose concentration. Similar observations were reported by Chau et al [15] and Ou et al [11]for insoluble fiber-rich fractions from Averrhoacarambola and wheat bran for ability to bind glucose and further decrease available glucose. Thus the vegetable insoluble fiber may be beneficial with respect to reducing amount of accessible glucose in the small intestine. 

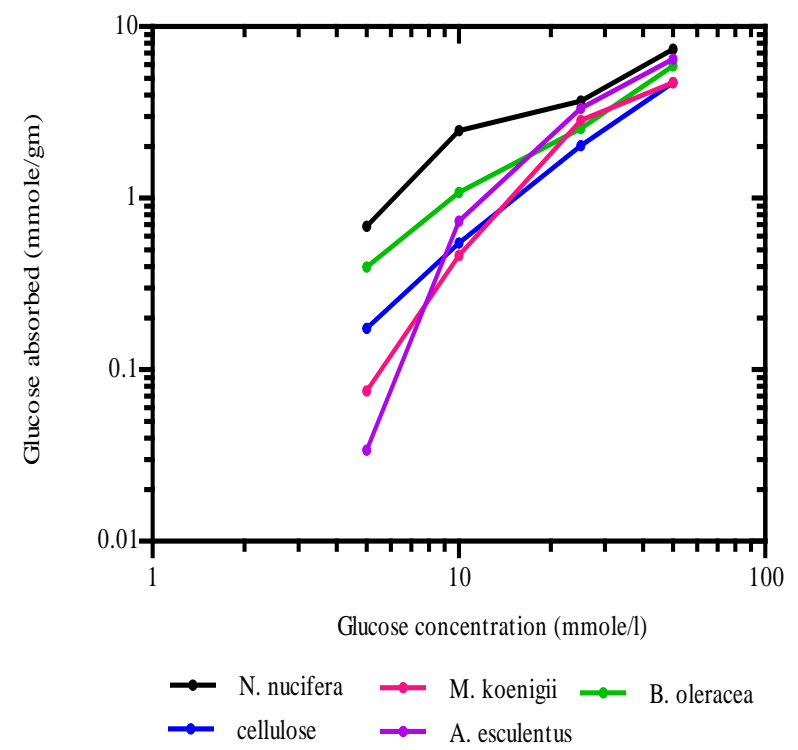

Figure 1. Log graph of Glucose absorbed vs. Glucose concentration

\subsection{Determination of Glucose Diffusion}

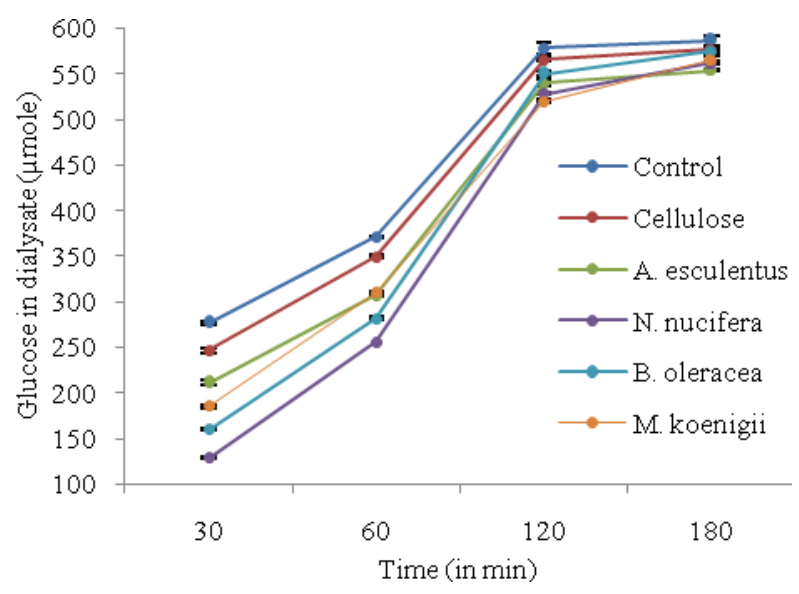

Figure 2. Effect of insoluble fibers on Glucose diffusion with respect to time

In this study, effect of vegetable insoluble fibers on glucose diffusion was compared with that of control from $30 \mathrm{~min}$ to $180 \mathrm{~min}$. It was observed that, all the fibers significantly $(\mathrm{p}<0.01)$ decreased diffusion of glucose across dialysis membrane as compared to controlas seen in Figure 2. The glucose contents in the dialysate among the vegetable fibers and cellulose ranged from $128.82 \pm 1.06$ $246.85 \pm 2.75 \mu \mathrm{mol}$ (at $30 \mathrm{~min}$ ) to $553.72 \pm 0.61-576.72$ $\pm 0.93 \mu \mathrm{mol}$ (at $180 \mathrm{~min}$ ). Glucose diffusion was lowest in $N$. nucifera at 30 and $60 \mathrm{~min}(128.82 \pm 1.06$ and $256.21 \pm$ $0.70 \mu \mathrm{mol})$ as compared to control and other fibers. After incubation for $180 \mathrm{~min}$, the glucose content in dialysate was reduced by all the fibers tested as compared to that of control (586.26 $\pm 5.71 \mu \mathrm{mol})$ however reduction was highest in $A$. esculentus (553.72 $\pm 0.61 \mu \mathrm{mol})$ and lowest in cellulose $(576.72 \pm 0.93 \mu \mathrm{mol})$. Maximum glucose diffusion decreased in the order control $>$ cellulose $>B$. oleracea $>M$. koenigii $>N$. nucifera $>A$. esculentus. Chau et al [15] suggested that the delay in diffusion could possibly attributed to their glucose adsorption capacities andcomplex meshwork of fibers which makes glucose unavailable fordiffusion [5]. The above result revealed that the all insoluble fiber efficiently decrease the glucose diffusion across dialysis membrane with different degree of diffusion depending on vegetable source, thereby controlling glucose level.

\subsection{Effect of Fibers on GDRI}

Glucose dialysis retardation index (GDRI) is a useful in vitro index to predict the effect of a fiber on the delay in glucose absorption in the gastrointestinal tract $[6,11]$. Effects of insoluble fibers on GDRI with respect to time arereported in Table 1. GDRI maximum value was reached after $30 \mathrm{~min}$ for all fiber tested and values were reduced as time increases. At $30 \mathrm{~min}$, the GDRI of the all vegetable insoluble fibers (23.82-53.46\%) were significantly $(\mathrm{P}<0.05)$ higher than that of cellulose (10.81\%). Similar trend was observed at 60,120 and 180 min of incubation. Further, it was observed that $N$. nucifera fibers have the higher GDRI values amongst other studied fibers at $30 \mathrm{~min}$ (53.46\%) till $60 \mathrm{~min}$ (30.98\%). Based on above results, an insoluble fiber from different sources showing high retardation index and possibly helps in showing hypoglycemic effect.

\begin{tabular}{|c|c|c|c|c|}
\hline \multirow{2}{*}{$\begin{array}{l}\text { Insoluble } \\
\text { Fiber }\end{array}$} & \multicolumn{4}{|c|}{ GDRI } \\
\hline & $30 \mathrm{~min}$ & $60 \mathrm{~min}$ & $120 \mathrm{~min}$ & $180 \mathrm{~min}$ \\
\hline Cellulose & $10.81 \pm 0.99^{\mathrm{a}}$ & $5.81 \pm 0.53^{f}$ & $2.08 \pm 0.37^{\mathrm{j}}$ & $0.95 \pm 0.16^{\mathrm{n}}$ \\
\hline $\begin{array}{c}\text { A. } \\
\text { esculentus }\end{array}$ & $23.82 \pm 0.92^{b}$ & $17.21 \pm 0.34^{\mathrm{g}}$ & $6.62 \pm 0.64^{\mathrm{jl}}$ & $4.90 \pm 0.10^{\text {no }}$ \\
\hline N. nucifera & $53.46 \pm 0.38^{c}$ & $30.98 \pm 0.19^{h}$ & $8.59 \pm 0.18^{\mathrm{km}}$ & $3.50 \pm 0.42^{\text {no }}$ \\
\hline B. oleracea & $42.13 \pm 0.64^{\mathrm{d}}$ & $24.07 \pm 0.62^{\mathrm{i}}$ & $4.86 \pm 0.43^{1}$ & $1.27 \pm 0.34^{\mathrm{P}}$ \\
\hline M. koenigii & $33.01 \pm 0.77^{\mathrm{e}}$ & $16.34 \pm 0.41^{\mathrm{g}}$ & $10.07 \pm 0.28^{\mathrm{m}}$ & $2.25 \pm 0.90^{\circ}$ \\
\hline \multicolumn{5}{|c|}{$\begin{array}{l}\text { a-m, values in the same column with same superscript are not } \\
\text { significantly different at } p<0.001\end{array}$} \\
\hline
\end{tabular}

\subsection{Effect of Fibers on $\alpha$-amylase Activity}

Effect of fibers on $\alpha$-amylase activity is presented in terms of glucose production ( $\mu \mathrm{g} / \mathrm{h} / \mathrm{g}$ of fiber) and enzyme inhibitory activity (in \%) isshown in Table 2 and Figure 3. Activity of $\alpha$-amylase was influenced significantly by insoluble fibers. The glucose production rate was lower in all fiber than that of control. The amount of glucose produced in test for $N$. nucifera $(672.59 \pm 5.13 \mu \mathrm{g} / \mathrm{h} / \mathrm{g})$ was significantly $(P<0.01)$ lower than that of control $(774.81 \pm 6.79 \mu \mathrm{g} / \mathrm{h})$. The reduction in glucose production can also be interpreted in terms of increase in enzyme inhibitory activity. The Table 4 revealed that $N$. nucifera fiber could exhibit a stronger effect in reducing the activity of alpha-amylase (by $13.19 \%$ ) as compared to those of cellulose $(9.94 \%), B$. oleracea (8.80\%), A. esculentus (7.84\%)and M. koenigii (6.50\%). These result revealed that vegetable fiber could exhibit an effect in decreasing amylase activity, with $N$. nucifera having the highest inhibitory activity. The variations in the inhibitory activity among the studied fibers showed that the inhibition depended on the source of vegetable fiber. This effect of insoluble fibers might be due to several possible factors such as fiber concentration, presence of inhibitor on fibers, capsulation of starch \&enzyme by fibersand 
direct adsorption of enzyme on fibers, thereby reduces accessibility of the starch leading to the decrease in amylase activity $[8,15]$. The differential in reduction of enzyme activity could be due to compositional difference in insoluble fiber from different sources.

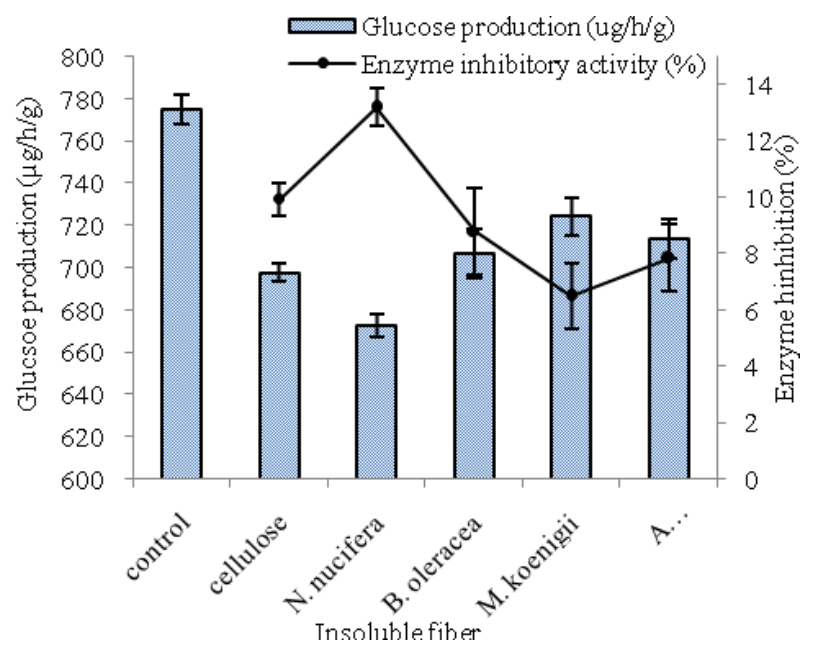

Figure 3. Effect ofvarious insoluble fibers on $\alpha$-amylase activity

\subsection{Binding Capacity for Sodium Cholate}

The Percentage of sodium cholate binding to vegetable insoluble fiberis shown in Table 4 and results are also expressed as sodium cholate binding in terms of mmole per gm fiber in Table 2 and Figure 4. All tested insoluble fibers were capable to interact with sodium cholate with different degree of binding. The percentage of sodium cholate bound to fiber ranges from 1.17-10.11\% (5.82 $50.55 \mathrm{mmole} / \mathrm{g})$. Among these fibers, N. nucifera was most effective, showed significantly $(\mathrm{P}<0.01)$ highest binding capacity of $10.11 \%$ (50.55 $\pm 0.10 \mathrm{mmole} / \mathrm{g}$ ) for sodium cholate. Further, $A$. esculentus, B. oleracea and $M$. koenigii showed comparatively low absorption of sodium cholate, 8.34, 8.23 and $8.06 \%(41.71 \pm 1.38,41.18 \pm 3.02$ and $40.26 \pm 0.91 \mathrm{mmole} / \mathrm{g})$ respectively and lowest binding was observed with cellulose of $1.17 \%$ (5.82 \pm $1.60 \mathrm{mmole} / \mathrm{g})$. Binding is a result of hydrophobic interaction between insoluble fiber and sodium cholate [22]. Dongowski G. [21]showed that dietary fiber preparations from a large group of cereals, fruits and vegetables were able to bind bile acids in vitro. In one of the recent study, Hatin et al [23] reported that the binding capacity of synthetic fibers for bile salt were very low. Wang et al [17] showed binding capacities of insoluble fibers from various seaweeds $(7-27 \mathrm{mmol} / \mathrm{g})$ which is comparatively lower than vegetable fibers investigated in the present study $(40.26-50.55 \mathrm{mmol} / \mathrm{g})$. This further indicates that the studied vegetable fiber has good hypocholesterolemic effect.

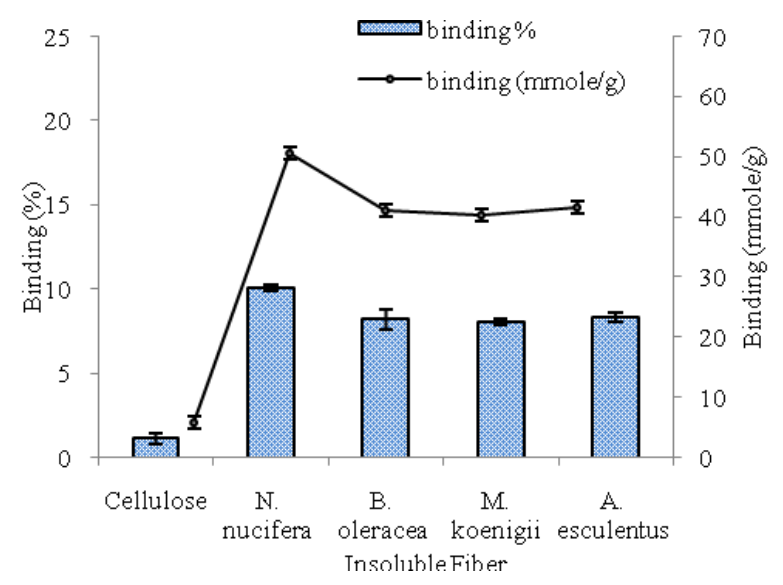

Figure 4. Sodium cholate binding capacity of insoluble fibers

Table 2. Effects of fibers on $\alpha$-amylase activity and sodium cholate binding capacity

\begin{tabular}{|c|c|c|c|c|}
\hline \multirow[b]{2}{*}{ Fibers } & \multicolumn{2}{|l|}{ Amylase activity } & \multicolumn{2}{|c|}{ Sodium Cholate Binding capacity } \\
\hline & $\begin{array}{l}\text { Glucose production } \\
(\mu \mathrm{g} / \mathrm{h} / \mathrm{g})\end{array}$ & $\begin{array}{l}\text { Enzyme inhibitory } \\
\text { Activity (\%) }\end{array}$ & $\begin{array}{l}\text { Binding } \\
\text { (in mmole/g) }\end{array}$ & $\begin{array}{l}\text { Binding } \\
\text { (in \%) }\end{array}$ \\
\hline No fibers & $774.81 \pm 6.79^{\mathrm{a}}$ & - & - & - \\
\hline Cellulose & $697.78 \pm 4.44^{\mathrm{b}}$ & $9.94 \pm 0.57^{d}$ & $5.82 \pm 1.60^{\mathrm{f}}$ & $1.17 \pm 0.32^{\mathrm{f}}$ \\
\hline Nelumbo nucifera & $672.59 \pm 5.13^{c}$ & $13.19 \pm 0.66^{\mathrm{e}}$ & $50.55 \pm 0.10^{\mathrm{g}}$ & $10.11 \pm 0.20^{\mathrm{g}}$ \\
\hline Brassica oleracea & $706.67 \pm 11.76^{\mathrm{b}}$ & $8.80 \pm 1.52^{d}$ & $41.18 \pm 3.02^{\mathrm{h}}$ & $8.24 \pm 0.60^{\mathrm{h}}$ \\
\hline Murraya koenigii & $724.44 \pm 8.89^{b}$ & $6.50 \pm 1.15^{\mathrm{d}}$ & $40.26 \pm 0.91^{\mathrm{h}}$ & $8.05 \pm 0.18^{h}$ \\
\hline Abelmoschus esculentus & $714.07 \pm 9.25^{\mathrm{b}}$ & $7.84 \pm 1.19^{d}$ & $41.71 \pm 1.37^{\mathrm{h}}$ & $8.34 \pm 0.27^{\mathrm{h}}$ \\
\hline
\end{tabular}

$\mathrm{a}-\mathrm{h}$, values in the same column with same superscript are not significantly different at $\mathrm{p}<0.001$

\section{Conclusion}

The results revealed that the studied vegetable insoluble fiber could effectively adsorb glucose, retard the glucose diffusion, inhibit the $\alpha$-amylase activity and bind sodium cholate. The $N$. nucifera showed highest hypoglycemic effect followed by $B$. oleracea, $M$. koenigii, $A$. esculentu. In case of hypocholesterolemic study $N$. nucifera exhibited highest sodium cholate binding capacity and rest all of the vegetable fiber showed comparable effect. Since $N$. nucifera (lotus stem) insoluble fiber showed the most promising results, thus it can be more often included in the diet for its suggestive health promoting role.

\section{Acknowledgement}

The authors would like to thanks UGC-SAP for the financial support of the present work.

\section{References}

[1] Kay, R. M., "Review: Dietary fiber”, Journal of lipid research, 32. 221-242. 1982.

[2] Tungland, B. C.and Meyer, D., "Nondigestible Oligo- and Polysaccharides (Dietary Fiber): Their Physiology and Role in Human Health and Food", Comprehensive Reviews in Food Science and Food Safety, 3. 90-109. 2002. 
[3] Tucker, L.A.and Thomas, K.S., "Increasing Total Fiber Intake Reduces Risk of Weight and Fat Gains in Women”, The Journal of Nutrition, 139(3). 576-581. 2009.

[4] Fuchs, C.S., Giovannucci, E.L., Colditz, G.A., Hunter, D.J., Tampfer, M.J., Rosner, B., Speizer, F.S.and Willett W.C., "Dietary fiber and the Risk of Colorectal Cancer and Adenoma in Women”, The New England Journal of Medicin, 340(3). 169-176. 1999.

[5] Lattimer, J. M. andHaub M. D., "Effects of Dietary Fiber and Its Components on Metabolic Health”, Nutrient, 2. 1266-1289. 2010.

[6] Longstreth, G.F., Thompson, W.G., Chey, W.D., Houghton, L.A., Mearin, F. and Spiller, R.C., "Functional Bowel Disorders," Gastroenterology, 130, 1480-1491. 2006.

[7] Diez, R., Garcia, J.J., Diez, M.J., M Sierra, M., Sahagun, A.M., Calle, A.P. and Fernandez, N., "Hypoglycemic and Hypolipidemic Potential of a High Fiber Diet in Healthy versus Diabetic Rabbits,” BioMed research International, 1-8. 2013.

[8] Bisoi, P. C., Sahoo, G., Mishra, S. K., Das, C. and Das, K. L., "Hypoglycemic Effects of Insoluble Fiber Rich Fraction of Different Cereals and Millets”, Journal of Food Processing and Technology, 3(7) 1-11. 2012.

[9] Ahmed, F., Sairam, S. and Urooj, A., "In vitro hypoglycemic effects of selected dietary fiber sources”, Journal of Food Science and Technology, 48(3). 285-289. 2011.

[10] Chau, C.F., Huang, Y. L. and Lee, M. H., "In Vitro Hypoglycemic Effects of Different Insoluble Fiber-Rich Fractions Prepared from the Peel of Citrus SinensisL. cv. Liucheng.The Journal of Agricultural and Food Chemistry,51, 6623-6626. 2003.

[11] Ou, S., Kwok, K., Li, Y. and Fu, l., "In vitro study of possible role of dietary fiber in lowering postprandial serum glucose," The Journal of Agricultural and Food Chemistry, 49. 1026-1029. 2001.

[12] Kahlon, T. S., Chiu, M. M. and Chapman, M. H., "In Vitro BileAcid-Binding of Whole vs. Pearled Wheat Grain", Cereal Chemistry, 86(3), 329-332. 2009.

[13] Kumar, M., Nagpal, R., Kumar, R., Hemalatha, R., Verma, V., Kumar, A., Chakraborty, C., Singh, B., Marotta, F., Jain, S. and Yadav, H., "Cholesterol-Lowering Probiotics as Potential
Biotherapeutics for Metabolic Diseases”, Experimental Diabetes Research. 1-14. 2012.

[14] Mishra, A. and Jha, S., "in vitro postprandial glucose lowering effect of dietary fibers isoltated from Tamarindusindica and cassia fistuka seeds”, American Journal of Food Technology, 6(5). 435440. 2011.

[15] Chau, C.F., Chen, C.H. and Lin, C.Y., "Insoluble fiber-rich fractions derived from Averrhoacarambola: hypoglycemic effects determined by in vitro methods", LWT-Food Science and Technology, 37. 331-335. 2004.

[16] Anderson, J. W., Story, L., Sieling, B., Chen, W. J., Petro, M. S. and Story, J., "Hypocholesterolemic effects of oat-bran or bean intake for hypercholesterolemic men”,The American Journal of Clinical Nutrition, 40. 1146-1155. 1984.

[17] Wang, W., Onnagawa, M., Yoshie, Y. andSuzuki, T., "Binding of bile salts to soluble and insoluble dietary fibers of seaweeds", Fisheries science, 67. 1169-1173. 2001.

[18] Dongowski, G., "Interactions between dietary fibre-rich preparations and glycoconjugated bile acids in vitro", Food Chemistry, 104(1). 390-397. 2006.

[19] Sreenivas, K.M. andlele, S.S., "Prebiotic activity of gourd family vegetable fibres using in vitro fermentation”, Food Bioscience, 1. 26-30. 2013.

[20] Zhang N., Huang, C. and Ou, S., "In vitro binding capacities of three dietary fibers and their mixture for four toxic elements, cholesterol, and bile acid”, Journal of Hazardous Materials, 186. 236-239. 2011.

[21] Urbani, A. and Warne, T., "A colorimetric determination for glycosidic and bile salt-based detergents: applications in membrane protein research”, Analytical Biochemistry, 336. 117124. 2005.

[22] Yuanita, L., Suyono and Sanjaya, I. G. M., "The binding of cholic acid by hemi cellulose and pectin of yard-Long bean [Vignasesquipedalis(L.) Fruhw]", Journal of Food Science \& Engineering, 1(5). 348-353. 2011.

[23] Hatin, H. R. A. andEbrahimi H. R., "Screening of Bile Acid Binding Capacity of Some Synthetic Dietary Fiber”, Global Veterinaria, 10(4). 485-490. 2013. 